\title{
Assessment of Healing Potential of Formulated Herbal Cream on Burn Wound
}

\author{
Yogesh Shivhare, Alok Pal Jain* \\ Sarvepalli Radhakrishnan University, Bhopal (M.P.) India
}

\begin{abstract}
The current protocol of the study was planned to assess the healing potential of formulated herbal cream containing different medicinal plant extracts. Formulated herbal cream was containing the methanolic extract of Chenopodium album, Coccinia indica, Momordica dioica, Precitrullus fistulosus and Trichosanthes dioica with cream base. Formulated herbal cream was assessed pharmacologically for healing potential in burn wound model. The formulation showed a significantly higher contraction rate, shortened epithelialization period, better tensile strength and increase in hydroxyproline content in the burn wound model. Thus, it is concluded that formulation has the potential wound healing activity which justifying its use as wound healer.
\end{abstract}

Keywords: Formulation, Burn, Wound, Contraction

Article Info: Received 30 June 2019; $\quad$ Review Completed 10 Aug 2019; $\quad$ Accepted 18 Aug 2019; Available online 25 August 2019

\section{Cite this article as:}

Shivhare Y, Jain AP, Assessment of Healing Potential of Formulated Herbal Cream on Burn Wound, Journal of Drug Delivery and Therapeutics. 2019; 9(4-s):1191-1194 DOI: http://dx.doi.org/10.22270/jddt.v9i4-s.3874

*Address for Correspondence:

Dr. Alok Pal Jain, Sarvepalli Radhakrishnan University, Bhopal (M.P.) India

\section{INTRODUCTION}

The medicinal plants have been used by humans from the pre-historical times. Studies have pointed out that many drugs that are used in business have come from folk-use and use of plants by native cultures. ${ }^{1}$ Medicinal plants have a capable prospect because there are about half million plants around the world, and most of them their medical activities have not investigate yet, and their medical activities could be decisive in the treatment of present or future studies. ${ }^{2}$ Plants and their extracts have massive potential for the management and treatment of wounds. Treatment strategies for most of the time rely on topical application of the medicament with an aim to enhance wound healing. ${ }^{3}$ Chenopodium album, Coccinia indica, Momordica dioica, Precitrullus fistulosus and Trichosanthes dioica plants were used for the formulation of herbal cream for the treatment of burn wound. A burn is defined as spoil to the skin caused by excessive heat or mordant chemicals. The most frequent burn injuries result from contact to heat and chemicals. Burn injury is characterized as a kind of inflammation below the stratum corneum of the skin, which can progress either to spontaneous healing or can depreciate to further necrosis, depending on the approach to treatment. Different types of burn injuries are epidemiologically common in different parts of the world yet thermal burns and related injuries remain the most commonly reported cause of burn related deaths and disabilities. ${ }^{4}$ Several studies showed that burn infection is the main reason of mortality in patients with extensive burns. Therefore, many researchers tried to achieve proper treatment methods to reduce the risk of wound infections and to shorten the period of treatment of patients with burn wounds. ${ }^{5}$ Some of these treatments involve using topical antimicrobial agents which effectively reduce mortality rate of burns. Hence, the existing study was planned to assess the healing potential of formulated herbal cream with extracts of various plants.

\section{MATERIALS AND METHODS}

\section{Extraction of plant drugs}

All the plant leaves were collected from the various sources, dried and converted into moderately coarse powder. Powdered plant drugs (Chenopodium album, Coccinia indica, Momordica dioica, Praecitrullus fistulosus and Trichosanthes dioica) were packed in soxhlet apparatus and extracted with methanol as solvent. The solvent was removed and dried extract of each plant was found.

\section{Formulation of herbal cream}

Ingredient of oil phase was melted in a beaker by using water bath on constant stirring. Components of aqueous phase were mixed together and warmed to about same 
temperature of oil phase (up to $70^{\circ} \mathrm{C}$ ). The preservative methyl paraben and propyl paraban were added into aqueous phase and heated. Then oil phase was added to water phase little by little on constant stirring. Plant extracts were mixed with the prepared cream base individually with uniform stirring using a mechanical stirrer. Water was added finally and mixed.6,7 The formulated creams were stored in a suitable plastic container for further use. The composition of herbal cream was presented in table 1.

Table 1 Composition of Herbal Cream

\begin{tabular}{|l|l|l|}
\hline \multirow{5}{*}{ Oil Phase } & Ingredients & Qty. in \% \\
\hline \multirow{5}{*}{ Aqueous Phase } & Stearic acid & $2 \%$ \\
\cline { 2 - 3 } & White Beeswax & $5 \%$ \\
\cline { 2 - 3 } & Cetyl alcohol & $2 \%$ \\
\hline \multirow{5}{*}{ Plant Extracts } & Propylene glycol & $5 \%$ \\
\cline { 2 - 3 } & Glycerine & $5 \%$ \\
\cline { 2 - 3 } & Methyl Paraban & $0.5 \%$ \\
\cline { 2 - 3 } & $\begin{array}{l}\text { Propyl Paraban } \\
\text { album }\end{array}$ & $0.5 \%$ \\
\cline { 2 - 3 } & Coccinia indica & Upto $100 \%$ \\
\cline { 2 - 3 } & Momordica dioica & $5 \%$ \\
\cline { 2 - 3 } & $\begin{array}{l}\text { Praecitrullus } \\
\text { fistulosus }\end{array}$ & $5 \%$ \\
\cline { 2 - 3 } & $\begin{array}{l}\text { Trichosanthes } \\
\text { dioica }\end{array}$ & $5 \%$ \\
\hline
\end{tabular}

\section{Evaluation of herbal cream}

Formulated herbal cream was assessed by various evaluation parameters such as color, consistency, $\mathrm{pH}$, Viscosity and spreadability. 8,9

\section{Experimental animals}

Albino wistar rats weighing 100-150 g were used after approval of the institutional ethics committee. The animals were maintained at a temperature-controlled, well ventilated animal room for a period of 7 days prior to the experimental period. They were kept on standard pellet diet and water ad libitum.

\section{Treatment Protocol}

For burn wound model, animals of either sex weighed between 100 and $150 \mathrm{~g}$ were divided into three groups. The grouping of animals was shown in table 2.

Table 2: Grouping of Animals

\begin{tabular}{|l|l|}
\hline Group I & Control (Cream Base) \\
\hline Group II & Standard (0.1\% silver sulfadiazine cream) \\
\hline Group III & $\begin{array}{l}\text { Herbal cream formulated with methanolic } \\
\text { extracts of all selected plants }\end{array}$ \\
\hline
\end{tabular}

\section{Burn wound model}

Burn wounds were created on dorsal part of shaved rats using a metal rod $(1.5 \mathrm{~cm}$ diameter $)$ heated to $80-85^{\circ} \mathrm{c}$ and exposed for 20 seconds. After $24 \mathrm{~h}$, dead tissues were excised using sterile surgical blade. Control rats were dressed with cream base alone, while experimental rats were dressed with the cream formulated with plants extracts. All the rats were given regular dressing changes at every alternative day. In this model, wound contraction \& epithelialization period were evaluated. Wound contraction was measured as \% contraction in each 4 days after wound creation. ${ }^{10}$

\section{RESULTS AND DISCUSSION}

Formulated herbal cream was found greenish brown in colour with semisolid consistency. The formulation has 6.25 $\mathrm{pH}$ which was compatible with skin physiology. The viscosity and spreadability were found 5890 and 7.4 respectively. The findings were presented in table 3.

\section{Effect of formulated herbal cream on \% wound contraction of burn wound model}

The percentage of burn wound contraction was calculated and compared with control group. Formulated herbal cream treated group significantly promoted wound closure compared to control. Complete wound closure was observed in 20 days by formulated herbal cream when compared to control. The findings were shown in fig 1 .

\section{Effect of formulated herbal cream on epithelialization period of burn wound model}

The number of days required for complete epithelialization is shown in fig 2 . The number of days required for complete epithelialization was 11 days when compared to control.

\section{Effect of formulated herbal cream on tensile strength of burn wound model}

The mean tensile strength $\left(\mathrm{g} / \mathrm{mm}^{2}\right)$ of granulated tissue in control group and formulated herbal cream was found 301.19 and 434.71 respectively as shown in fig 3.

\section{Effect of formulated herbal cream on hydroxyproline} content of burn wound model

The hydroxyproline content (mg/g tissue) was found 27.12 for control group and 58.5 for formulated herbal cream as shown in fig 4.

\section{CONCLUSION}

From the present findings, it can be concluded that formulated herbal cream exhibited potent wound healing potential against thermal burn injury. The anti-burn activity of the formulated herbal cream could be attributed to the healing potential of its major components found in the extracts of these medicinal plants. However, still further research is acceptable to describe the mechanism of present findings and to evaluate the major phytoconstituents responsible for the burn healing property exhibited by formulated herbal cream.

\section{ACKNOWLEDGEMENT}

The authors are very thankful to the management of Sarvepalli Radhakrishnan University for providing necessary amenities for the completion of this study. 
Table 3 Evaluation parameters of formulated herbal cream

\begin{tabular}{|l|l|l|l|l|}
\hline Colour & Consistency & $\mathrm{pH}$ & Viscosity $(\mathrm{cp})$ & Spreadability (g×cm/sec) \\
\hline Greenish brown & Semisolid & 6.25 & 5890 & 7.4 \\
\hline
\end{tabular}
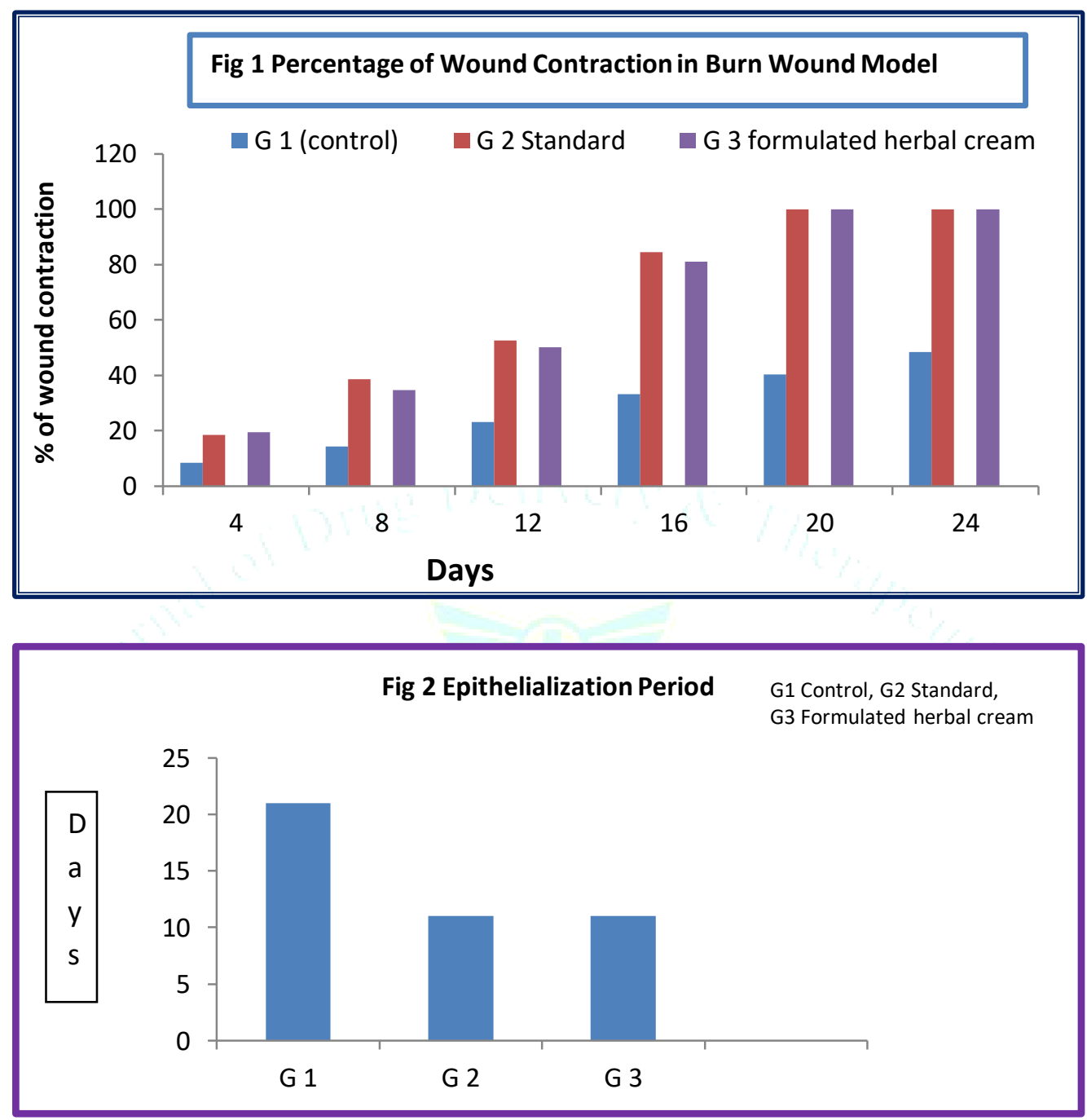

Fig 3 Effect of formulated herbal cream on tensile strength $\left(\mathrm{g} / \mathrm{mm}^{2)}\right.$

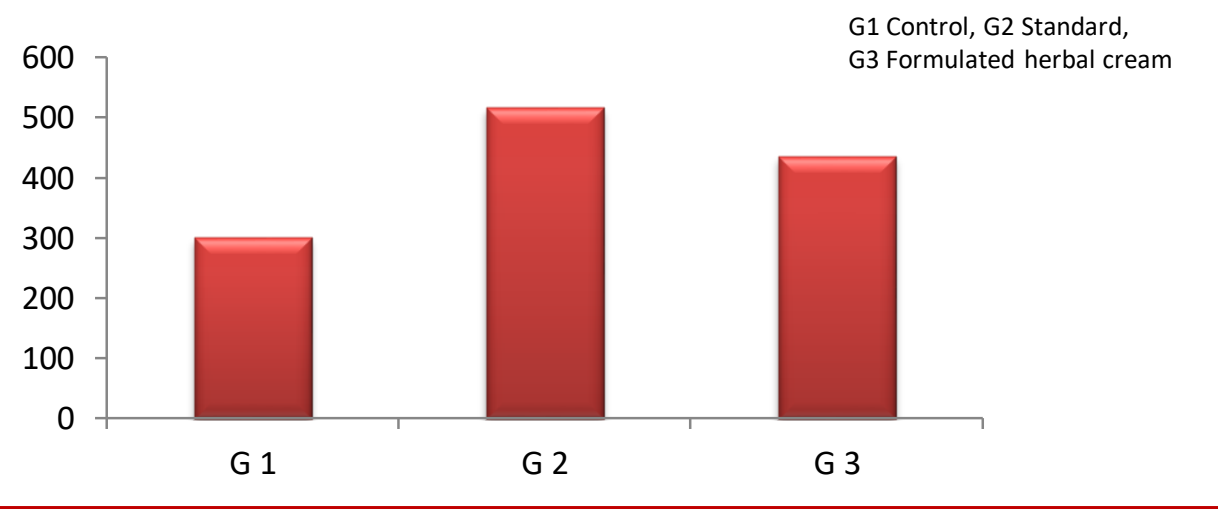


Fig 4 Effect of formulated herbal cream on hydroxyproline content ( $\mathrm{mg} / \mathrm{g}$ tissue)

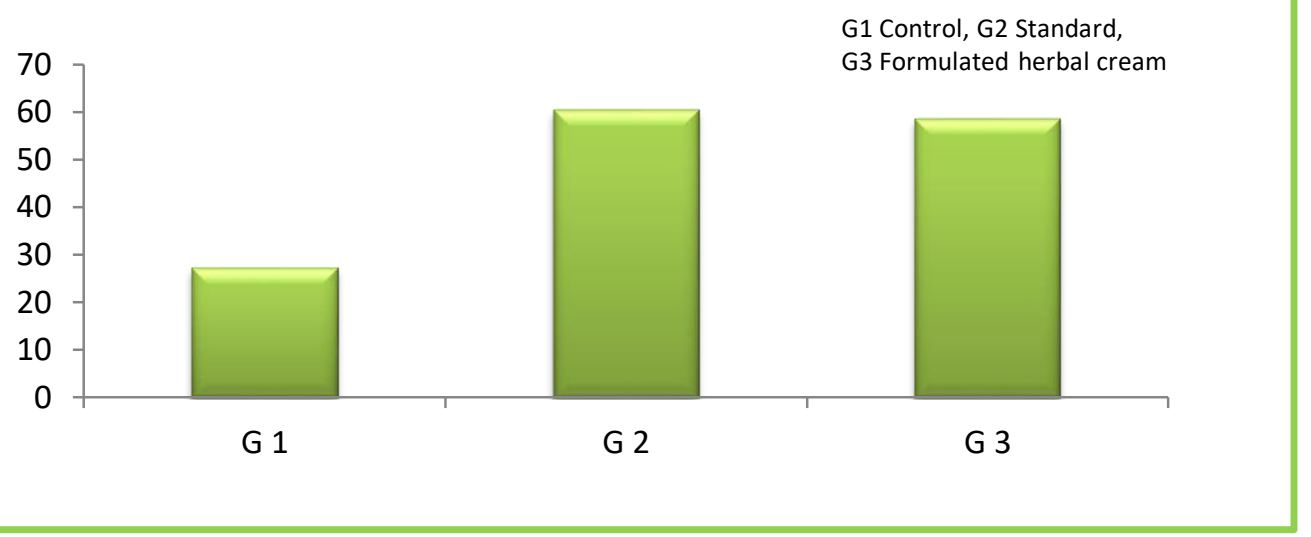

\section{REFERENCES}

1. Anonymous. 1994. Ethnobotany in the search for new drugs. Ciba Foundation Symposium 188, John Wiley and Sons, New York.

2. Fabricant DS, Farnsworth NR. The value of plants used in traditional medicine for drug discovery. Environ Health Perspective. 2001; 109:69-75.

3. Taylor Leslie ND. Plant Based Drugs and Medicines. Rain Tree Nutrition. 2000.

4. Bhatia Nitish, Singh Arunpreet, Sharma Rohit, Singh Amandeep, Soni Varinder, Singh Gurjeet, Bajaj Jaideep, Dhawan Ravi, Singh Balwinder. Evaluation of burn wound healing potential of aqueous extract of Morus alba based cream in rats. The Journal of Phytopharmacology. 2014; 3(6):378-383.

5. Manafi A, Kohanteb J, Mehrabani D, Japoni A, Amini M, Naghmachi M, Zaghi AH, Khalili N. Active immunization using exotoxin A confers protection against Pseudomonas aeruginosa infection in a mouse burn model. BMC Microbiology. 2009; 9:23.
6. Das Trailokya, Debnath Jiban, Nath Bipul, Dash Suvakanta. Formulation and evaluation of an herbal cream for wound healing activity. International Journal of Pharmacy and Pharmaceutical Sciences. 2014; 6 (2):693-697.

7. Nair Sujith S, Mathew Molly, Sreena K. Formulation and Evaluation of Herbal Cream containing Curcuma longa. International Journal of Pharmaceutical and Chemical Sciences. 2012; 1 (4):1362-1368.

8. Kubo I, Muroi H, Kubo A. Naturally Occurring Anti-acne Agents. Journal of Natural Products. 1994; 57(1):9-17.

9. Vijayalakshmi A, Tripura A, Ravichandiran V. Development and Evaluation of Anti- Acne Products from Terminalia arjuna Bark. International Journal of Chem Tech Research. 2011; 3(1):320-327.

10. Shanmuga Priya K, Gnanamani A, Radhakrishnan N, Babu Mary. Healing potential of Datura alba on burn wounds in albino rats. Journal of Ethnopharmacology. 2002; 83:193-199. 